mixed, or obstructive. ${ }^{3}$ The implications of apnoea have become widely known to many parents whose infants have experienced apnoeic or cyanotic episodes or who have previously lost infants with the sudden infant death syndrome.

There is a widely accepted dogma that infants who have had life threatening apnoeic episodes and siblings of victims are at increased risk of death. ${ }^{45}$ In these groups it would seem, therefore, logical and justifiable to attempt some form of monitoring, and it is surprising that many paediatricians are reluctant to provide respiratory monitors for use a home. In the United States apnoea programmes have become widely established, but often using expensive, technically complex, and sometimes misused equipment. ${ }^{6}$ Even so, it was interesting to read the interpretation of data from 11 Californian monitoring programmes that excessive deaths of high risk infants might have been prevented. ${ }^{6}$

In the United Kingdom we are fortunate to have had available for the past seven years a fairly inexpensive, uncomplicated monitor, originally described by B M Wright. ${ }^{7}$ Abdominal expansion is detected by means of a small pneumatic capsule whence pressure pulses are converted electronically into audible and visible signals, and an alarm sounds after a measured period of apnoea. This monitor is widely used in neonatal units and paediatric wards. Over a similar period of time have personally been informed of 165 cases of the syndrome in Leicestershire and have received 110 requests for respiratory monitors $(83$ for siblings of victims, 27 for babies with apnoea). All of the parents are made aware that monitors canno guarantee infant survival, but after instruction in the use of the monitor, guidance on mouth to nose resuscitation, and regular clinic attendance virtually all parents have found monitoring immensely reassuring.

It has helped many parents to sleep, reduced overt anxiety, and improved parent-child interaction. Three infants have been resuscitated after apnoea (all with respiratory infections). Another, with bronchiolitis, was brought to hospital because of monitor alarms. He required mechanical ventilation followed by tracheostomy and is alive and well. Two siblings of victims of the syndrome have died (aged 13 days and 19 months), but neither was connected to the monitor at the time and neither was a typical victim of the syndrome. Some infants with more frequent alarms during intercurrent infections have undergone respiratory and metabolic investigations. Fourteen families have re quested second monitors for subsequent siblings; five families declined a second monitor.

This experience leads me to conclude that home respiratory monitoring of previously apnoeic infants and siblings of victims of the sudden infant death syndrome is therapeutically important for parents and useful in alerting us to investigate and treat infants found to have more frequent alarms. Nationally more than 6000 pneumatic capsule devices have been bought, a proportion of which are used in home monitoring. To my knowledge no infant has died while actually using one of these monitors. This surprising statistic-considering that the infants monitored are those at increased risk-suggests that home monitoring in Britain may be helping to prevent some sudden deaths in infancy.

PeTER G F SWIFT

L.eicester General Hospital

Leicester CE5 4PW

1 Anonymous. Risk of cot deaths. Br Med f 1975;iii:664.

2 Stanton AN. "Near-miss." Cot deaths and home monitoring. Stanton AN. "Near-miss."
BrMed f 1982;285:1441-2.

3 Guilleminault C, Heldt G, Powell N, Riley R. Small upper airway in near-miss sudden death syndrome infants and their families. Lancet 1986;i:402-7.

4 Oren J, Kelly D, Shannon DC. Indentification of a high-risk group for SIDS among infants who were resuscitated for sleep apnoea. Pediatrics 1986;77:495-9.

Peterson DR, Chinn NM, Fisher LD. The sudden infant deat syndrome: repetitions in families. $\mathcal{F}$ Pediatr 1980;97:265-7.

6 Davidson Ward SL, Keens TG, Chan LS, et al. Sudden infant death syndrome in infants evaluated by apnoea programmes in California. Pediatrics 1986;77:451-8.

Wright BM. An abdominal respiratory detector. 7 Physiol (Lond) 1977;271:11-2.

SIR,-Though I must accept that there is a lack of scientific proof that apnoea monitors help avert death in the siblings of victims of the sudden infant death syndrome, Professor Hamish Simpson fails to bring out one potential benefit of monitoring that cannot easily be assessed in scientific publications (30 May, p 1367).

As the parent of a victim of the sudden infant death syndrome and the subsequent user (currently for the second time) of an apnoea monitor, I should like to emphasise that we are dealing with a situation that concerns not only the sibling, who is possibly at risk, and his or her medical advisers but also the parents. I am sure that we can all imagine the agony of a parent who has suffered the loss of a child by the sudden infant death syndrome and who subsequently has to care for another child who might be at risk. It is bad enough to have to keep a baby under constant surveillance during normal daylight hours without having to try to observe one continuously during the night.

Professor Simpson thankfully does suggest that a decision whether siblings of victims should be monitored has to be made on the merits of each individual case with medical judgment and close family involvement. For many distressed parents the supply of a monitor will enable them to remain sane. While the incessant tick continues the child is still alive.

Rheumatology Department,

DAVID M REID

City Hospital,

Aberdeen AB2 IN]

\section{Penetration of antibiotics into the respiratory tract}

SIR,-We were interested to read the leading article by Dr Jane Symonds ( 9 May, p 1181), and we agree that it is important to know the degree of lung tissue damage when choosing antibiotic regimens.

We wish, however, to correct an error in the article's reference to Cole et al's publication showing the efficacy of high dose amoxycillin ( $3 \mathrm{~g}$ 12 hourly) in an open study of patients with severe chronic bronchial suppuration.' These patients did not suffer from chronic bronchitis, as stated in the leading article, but from severe bronchiectasis. This is important because the severity and extent of tissue damage in such patients is significantly greater than that in patients with chronic bronchitis. Consequently, the high dose of antimicrobial drug was indicated to attempt to overcome such barriers to drug delivery. This has not yet been conclusively shown to be required for the treatment of chronic bronchitis.

We have, in fact, investigated further the efficacy of amoxycillin ( 3 g 12 hourly) in a double blind, placebo controlled study of 36 patients with bronchiectasis and persistent daily purulent sputum expectoration. ${ }^{2}$ Seventeen of the 36 patients had reported no response to conventional oral antibiotic courses. The patients were randomly allocated to receive either oral amoxycillin or placebo for 32 weeks. During treatment 24 hour purulent sputum volume decreased by a mean of more than half in 11 of $17(65 \%)$ patients in the amoxycillin group, compared with only five of
CURRIE

N D GARBETT

P J COLE

$19(26 \%)$ in the control group $(\mathrm{p}<0 \cdot 025)$. (The complete findings of the study are in preparation.)

This study confirms that a higher dose of amoxycillin than conventionally used has a role in management of bronchiectasis associated with daily purulent sputum.

ardiothoracic Institute

London SW3 6HP

Cole PJ, Roberts DE, Davies SF, Knight RK. A simple oral antimicrobial regimen effective in severe chronic bronchial
suppuration associated with culturable Haemophilus insuppuration associated with culturable Haemoph
fluenzae. I Antimicrob Chemother 1983;11:109-13.

2 Currie DC, Garbett ND, Chan KL, et al. Double blind randomised placebo controlled study of long term high dose antibiotic in patients with bronchiectasis. Clin Sci 1987;72:79.

\section{Infection by airborne Chlamydia} trachomatis

SIR,-The reply from Professor M Midulla and colleagues to our letter (23 May, p 1352) merits further comment.

In addition to describing the first case of alleged tetracycline resistance of and airborne infection with Chlamydia trachomatis Professor Midulla and colleagues seem to describe the first case of primary infection in the conjunctiva with spread to the genitalia - that is, chlamydial genital infection as a complication of chlamydial conjunctivitis. This is contrary to the accepted transmission routes of $C$ trachomatis. Can the authors suggest the actual mode of spread from the conjunctiva of the doctor to his wife's urethra and cervix?

The $C$ trachomatis strains from patients in our care who did not seem to respond to conventional treatment with tetracycline were also tested for antibiotic resistance in vitro. In all cases the minimum inhibitory concentration of tetracycline to the original strain and the resistant strain was precisely similar, indicating no acquisition of resistance but reinfection or non-compliance with the treatment regimen advised. We agree with Dr David Taylor Robinson (2 May, p 1161) that Professor Midulla and colleagues should release the strains so that reference centres can confirm by in vitro testing this potentially important finding of tetracycline resistance.

The authors did not perform tests to exclude chlamydial genital infection from the dentist's fiancée, and thus airborne infection cannot be assumed.

Mala Viswalingam

External Eye Diseases Clinic

BEN T GOH

JANET MANTEll

Diagnostic Clinic,

Moorfields Eye Hospital

J D TREHARNE

Institute of Ophthalmology,

London

Successful treatment of asymptomatic endometriosis: Does it benefit infertile women?

SIR,-Carefully conducted studies such as that by Dr Eric J Thomas and Professor Ian D Cooke (2 May, p 1117) make a valuable contribution towards the eventual resolution of the conundrum of endometriosis: its role in infertility. While we do not dispute that the presence of minimal endometriosis or treatment to eliminate the ectopic endometrial tissue may have little effect on fertility, we would make the following comments.

Data from this department ${ }^{1}$ have confirmed 